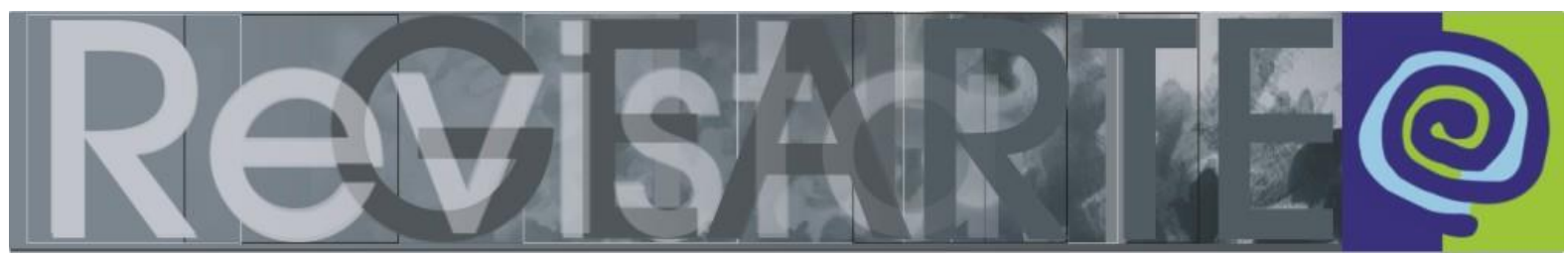

e-ISSN 2357-9854

\title{
Portugal, Educação Artística, Arte/Educação, Brasil
}

\author{
Umbelina Maria Duarte Barreto (Universidade Federal do Rio Grande do Sul, Brasil)
}

RESUMO - Portugal, Educação Artística, Arte/Educação, Brasil - Este Ensaio visual com referência ao VII Congresso Matéria-Prima realizado em Lisboa, Portugal, em 2018, propõe uma reflexão que inicia com uma pergunta que funciona como uma chave de abertura. O questionamento do discurso educativo e o levantamento de epistemologias da arte constituem o desenvolvimento desse ensaio. A sua exposição está mediada por uma seleção que atende a alguns objetivos traçados a partir do tema do Congresso: Transformar, criar, desafiar. Focaliza uma relação Brasil/Portugal enfatizando a Arte/educação e a Educação artística, como nomenclaturas utilizadas em um e em outro país. Relaciona algumas semelhanças e diferenças nas práticas de ensino da arte apresentadas no Congresso como uma das possibilidades da reflexão realizada.

PALAVRAS-CHAVE

Ensaio visual. Discurso educativo. Epistemologias da arte.

ABSTRACT - Portugal, Arts Education, Arts / Education, Brazil - This visual essay, in reference to the VII Matéria-Prima Congress held in Lisbon, Portugal, in 2018, proposes a reflection that starts with a question that functions as an aperture key. The questioning of the educational discourse and the survey of epistemologies of art constitutes the development of this essay. The exposure of the assay is mediated by a selection that meets some objectives outlined from the theme of the Congress: Transform, create, challenge. It focuses on a Brazil/Portugal relationship emphasizing art/education and artistic education as nomenclatures used in one and another country. It relates some similarities and differences in art teaching practices presented as one of the possibilities of the reflection performed.

\section{KEYWORDS}

Visual Essay. Educational Discourse. Epistemologies of Art. 


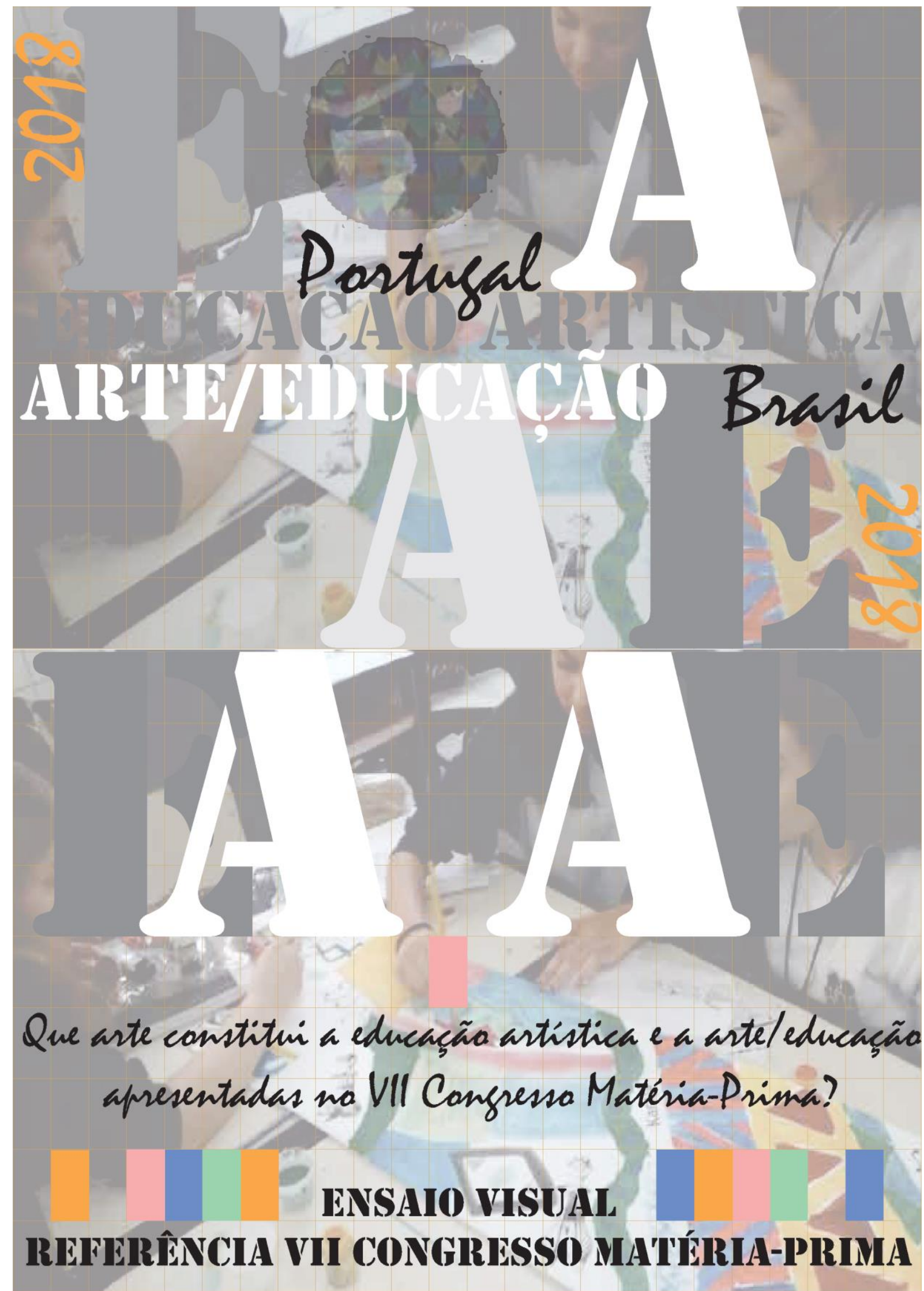

BARRETO, Umbelina Maria Duarte. Portugal, Educação Artística, Arte/Educação, Brasil. 592 Revista GEARTE, Porto Alegre, v. 5, n. 3, p. 591-599, set./dez. 2018

Disponível em: http://seer.ufrgs.br/gearte 
Cam que discusso educa a educação artistica apresentada no VII Congressa Matéria-Prima?

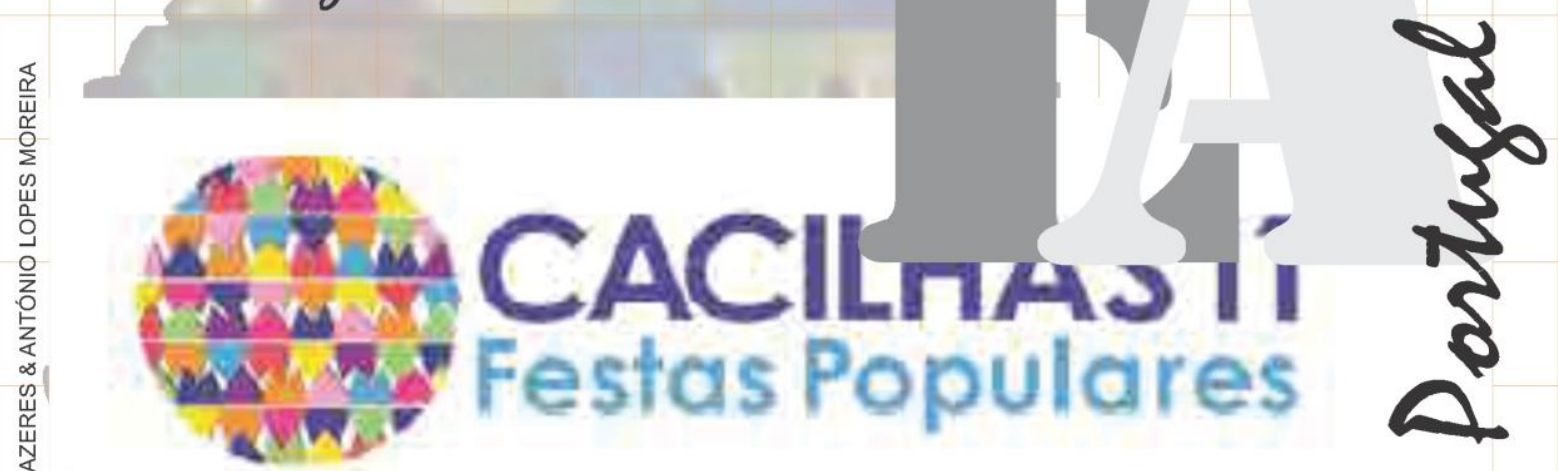

Com um discurso interdisciplinar que resgata a cultura popular no desenvolvimento educativo ao inserir a arte no universo da cultura.

A partir da interação com o cotidiano das comunidades, pesquisando e participando de concursos que aproximam o os alunos das manifestações culturais, como por exemplo, na elaboração da Identidade Visual das Festas de Cacilhas.

Com que discusso educa a arte/educação apresentada

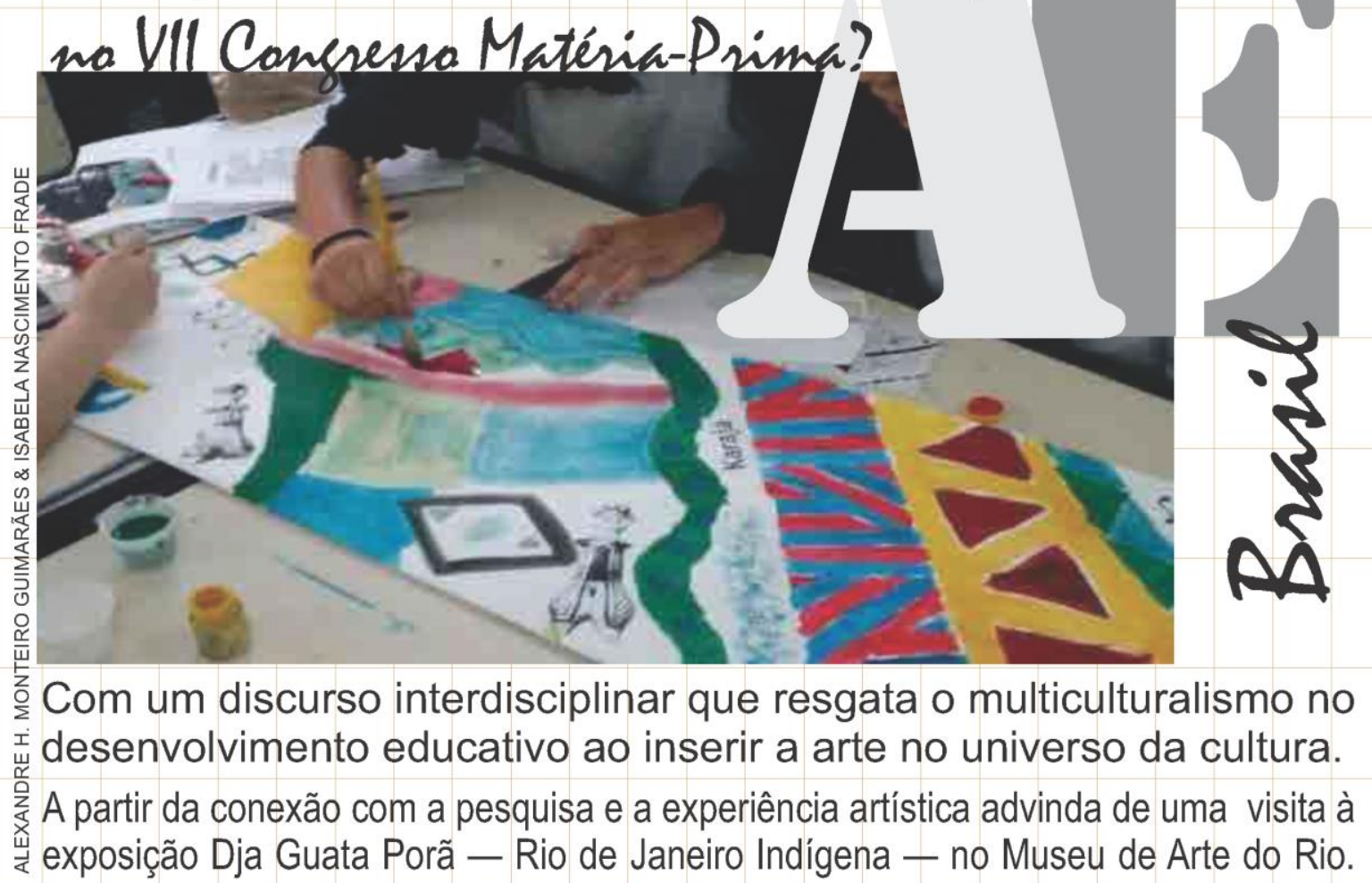


Com que discusso educa a arte/educaçäa apresentada no VII Congresso Matéria-Prima?
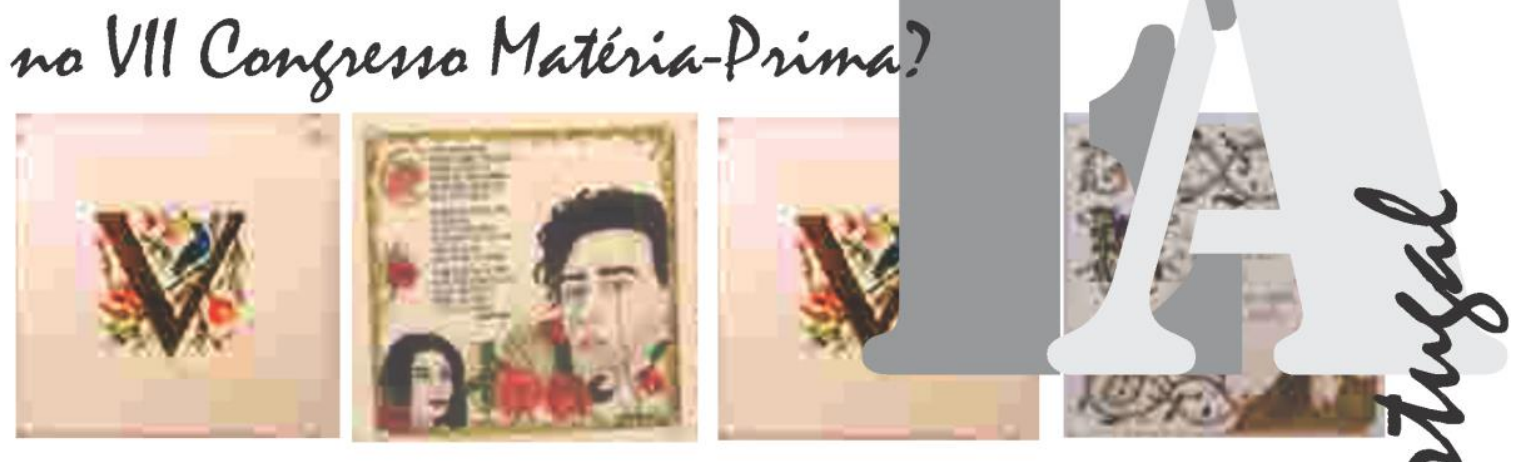

Com um discurso interdisciplinar que articula o texto escrito e o texto visual, enfatizando a arte no desenvolvimento educativo ao resgatar as relações

ü entre a imagem e a escrita.

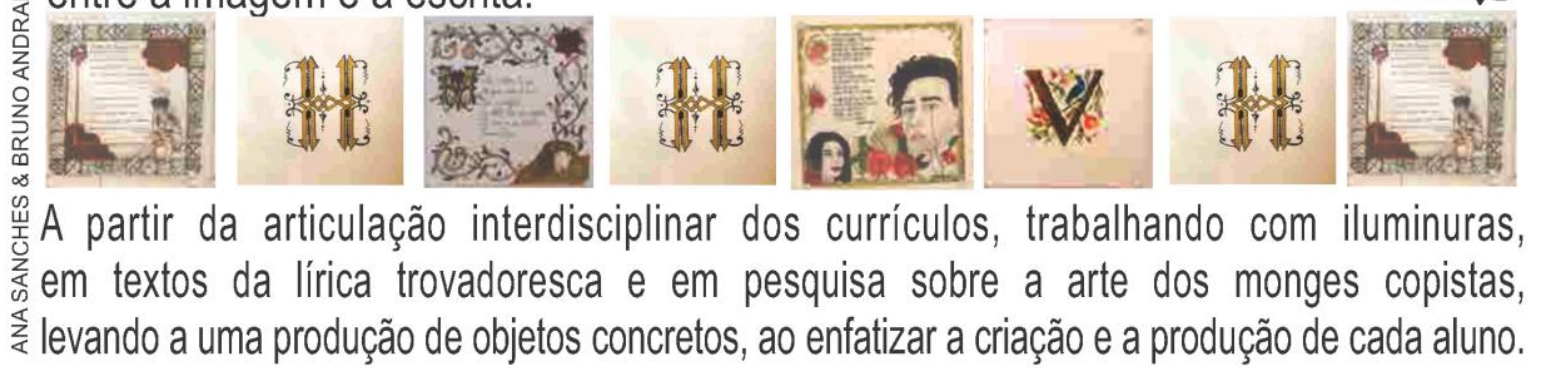

\section{Com que discusso educa a arte/educaçãa apresentada xa VII Congresso Matéria-Prima.}

Com um discurso sobre 0 ato criador, individual e coletivo, visto como práxis educativa, ao enfatizar a criação artística no desenvolvimento pedagógico do arte/educador colocando lado a lado processo, produto e mediação, em um processo dialético que envolve a autoria e a não-autoria.

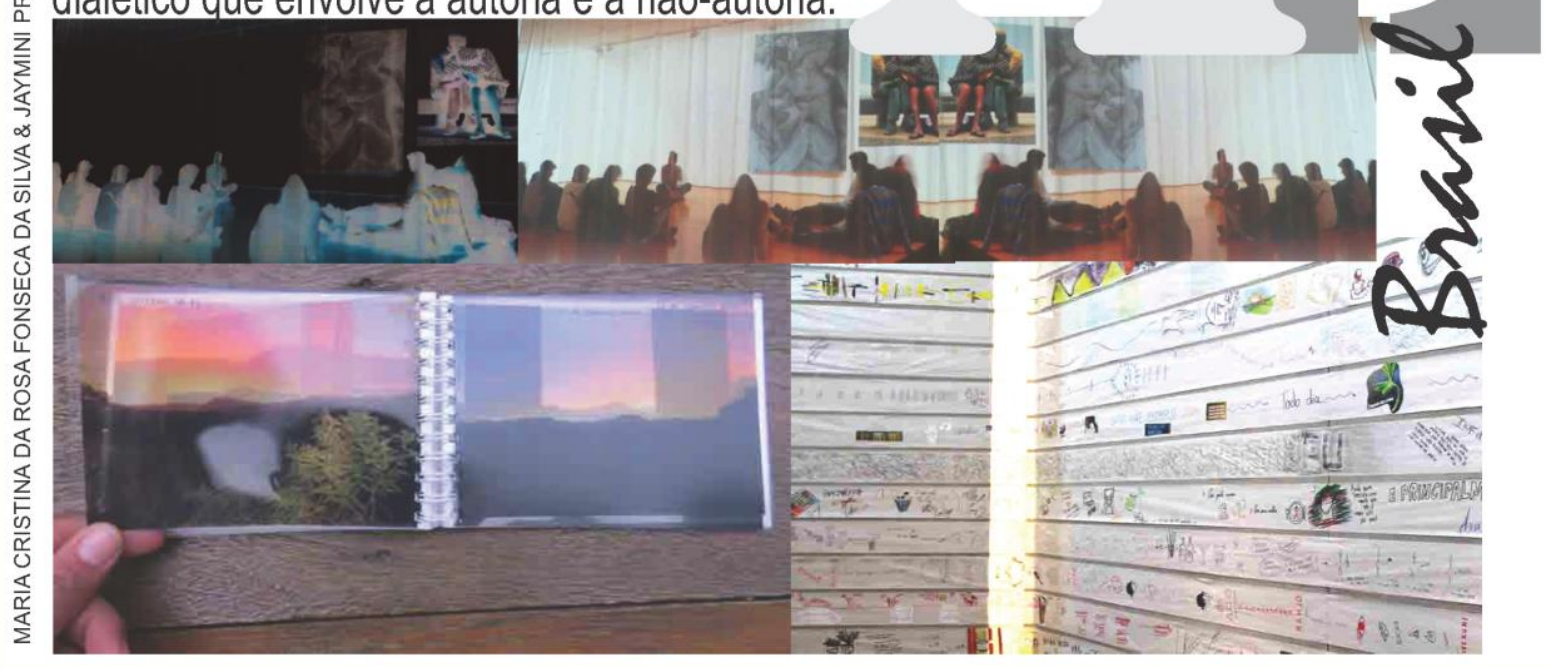

BARRETO, Umbelina Maria Duarte. Portugal, Educação Artística, Arte/Educação, Brasil. 
Qual a efistemologia da aste que pespassa a educação artistica $e$ a arte/educação apresentadas wo VII Congresso Matéria-Prima?

Desenho é dado como uma forma de desenvolvimento da 产 linguagem da arte ao focalizar a expressividade do gesto através da ampliação dos espaços didáticos.

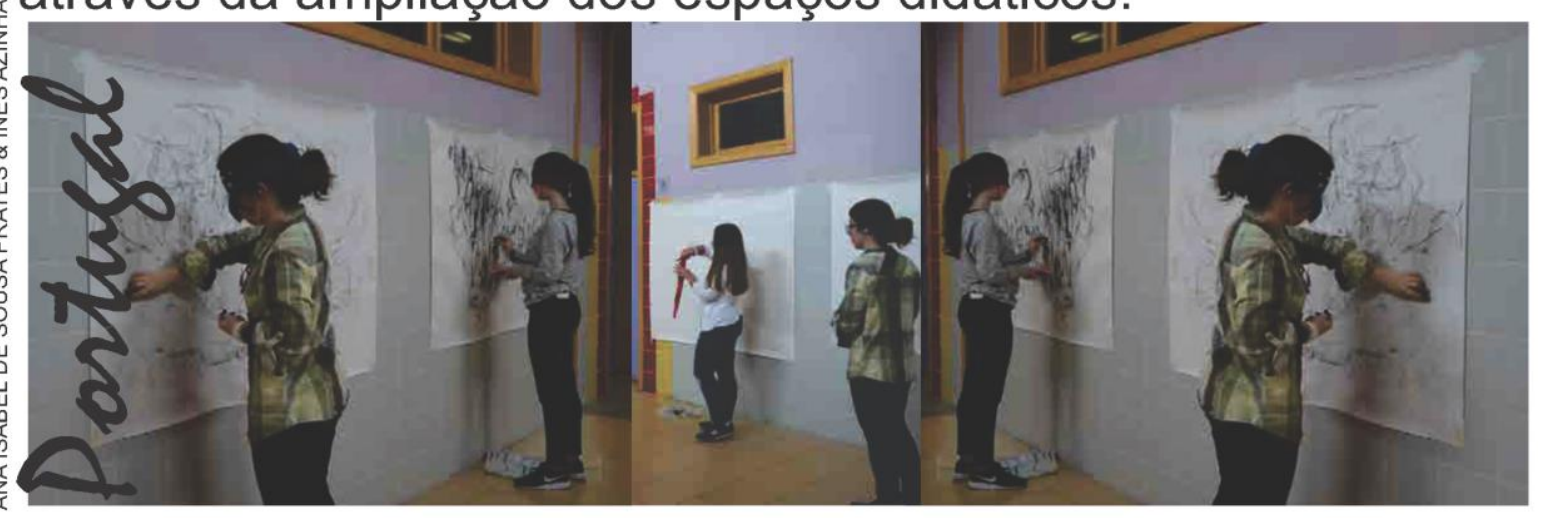

Qual a efistemologia da aste que pespassa a educaçãa artistica $e$ a arte/educaçãa apresentadas wa VII Consressa Matéria-Prima? O Desenho é dado como uma Porma de desenvolvimento da singuagem da arte ao focalizar a expressividade do gesto ự através da multiplicação dos instrumentos e da reorganização dos objetos no plano.

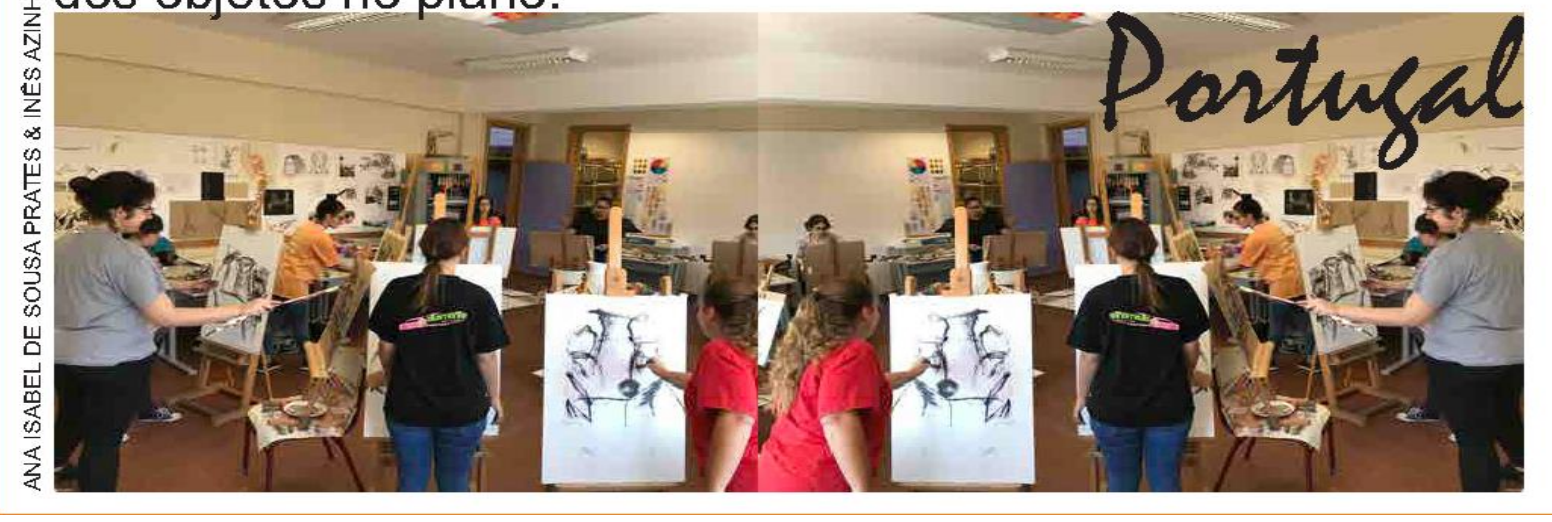

BARRETO, Umbelina Maria Duarte. Portugal, Educação Artística, Arte/Educação, Brasil.

595

Revista GEARTE, Porto Alegre, v. 5, n. 3, p. 591-599, set./dez. 2018. Disponível em: http://seer.ufrgs.br/gearte 
Qual a epistemologia da arte que perpassa a educaçäa artistica $e$ a arte/educaçäa?

A arte é focalizada como uma linguagem que perpassa a expressão corporal $e$ possibilita a experimentação de procedimentos técnicos através da exploração do movimento do corpo no espaço e da experiência no contato direto com artistas que apresentam em suas obras este diálogo corpo/espaço.
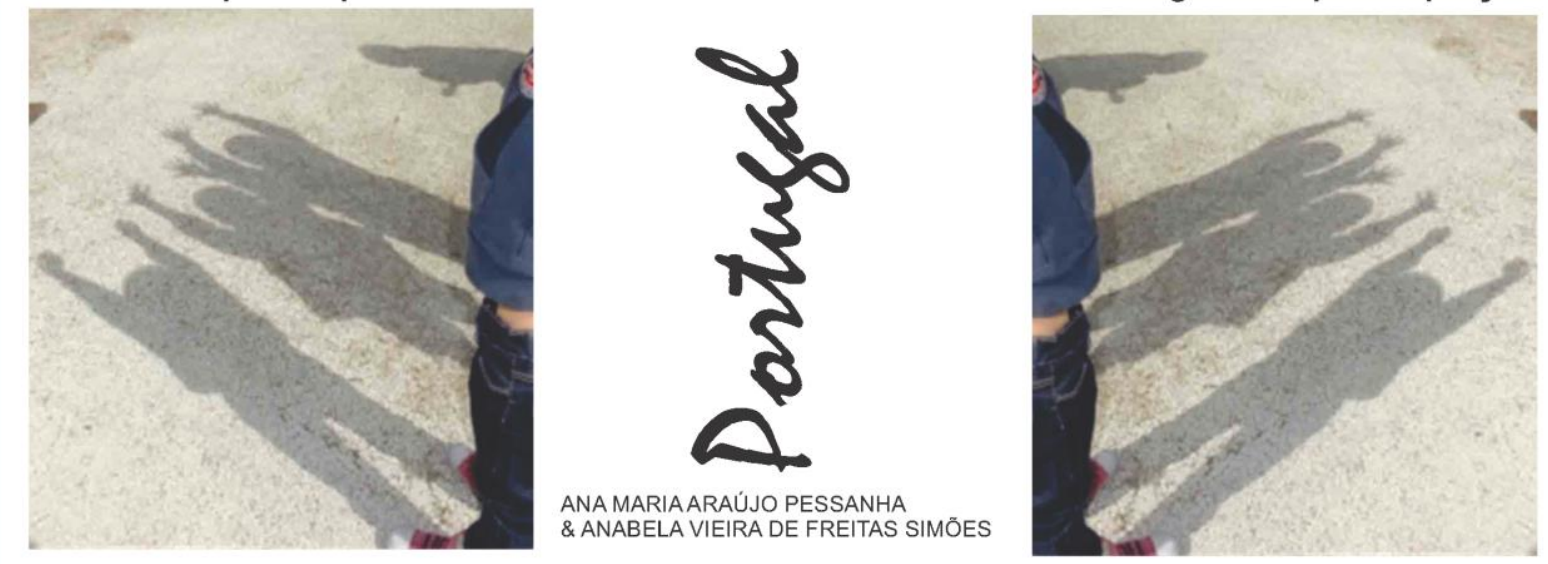

Qual a epistemologia da arte que perpassa $a$ educaçäa astistica $e$ a arte/educaçäa?

A arte é focalizada como uma linguagem que pressupõe a experiência em um cruzamento que envolve o corpo e o pensamento. Essa concepção leva ao entrelaçamento da pesquisa, da extensão e do ensino na formação de professores, em que são criados materiais didáticos e objetos de aprendizagem, definindo mudanças pedagógicas na Arte/Educação.

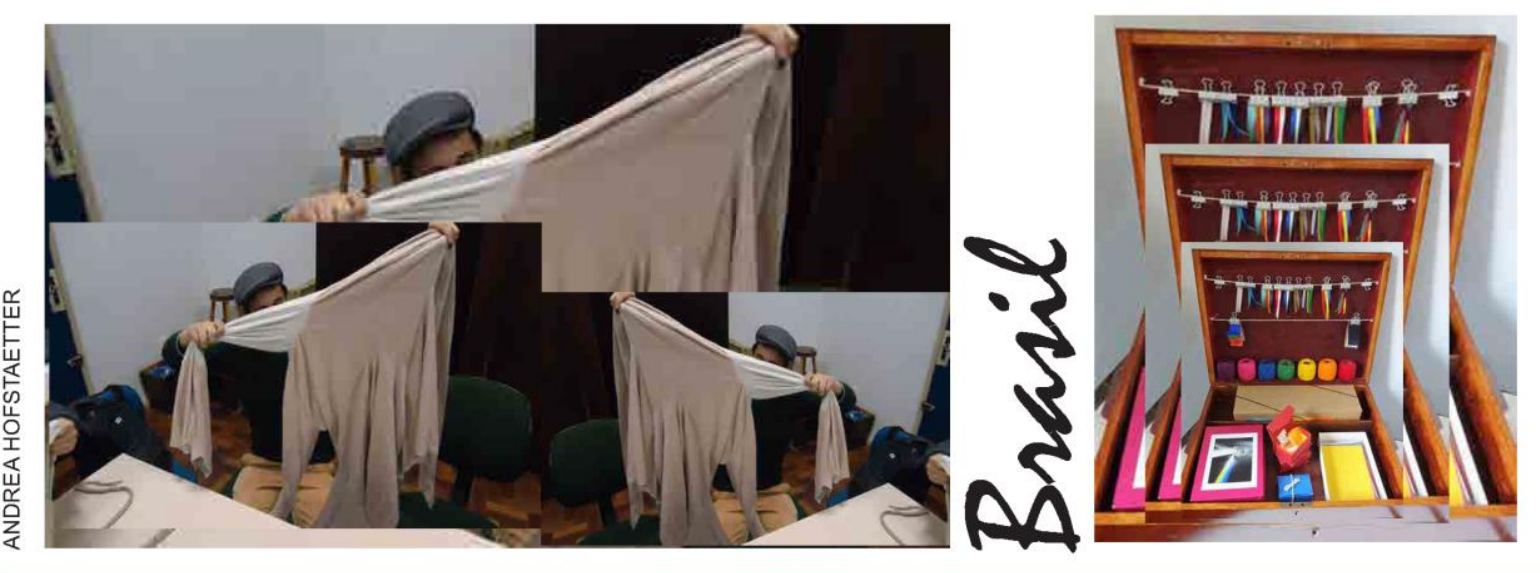

BARRETO, Umbelina Maria Duarte. Portugal, Educação Artística, Arte/Educação, Brasil.

596

Revista GEARTE, Porto Alegre, v. 5, n. 3, p. 591-599, set./dez. 2018 Disponível em: http://seer.ufrgs.br/gearte 
Qual a efistemologia da aste que pespassa a educaçãa artistica $e$ a arte/educaçãa? A arte é focalizada como uma linguagem integrada pela criação, gerando um processo e/ou um produto, e pela exposição, possibilitando a experiência da fruição e da leitura visual. Essa concepção possibilita o entrelaçamento da arte e da educação através da experiência artística envolvendo o aluno como autor e como fruidor, fazendo da exposição também uma forma de conhecimento artístico relacionada à visualidade reconstruída na relação visível/ invisível.
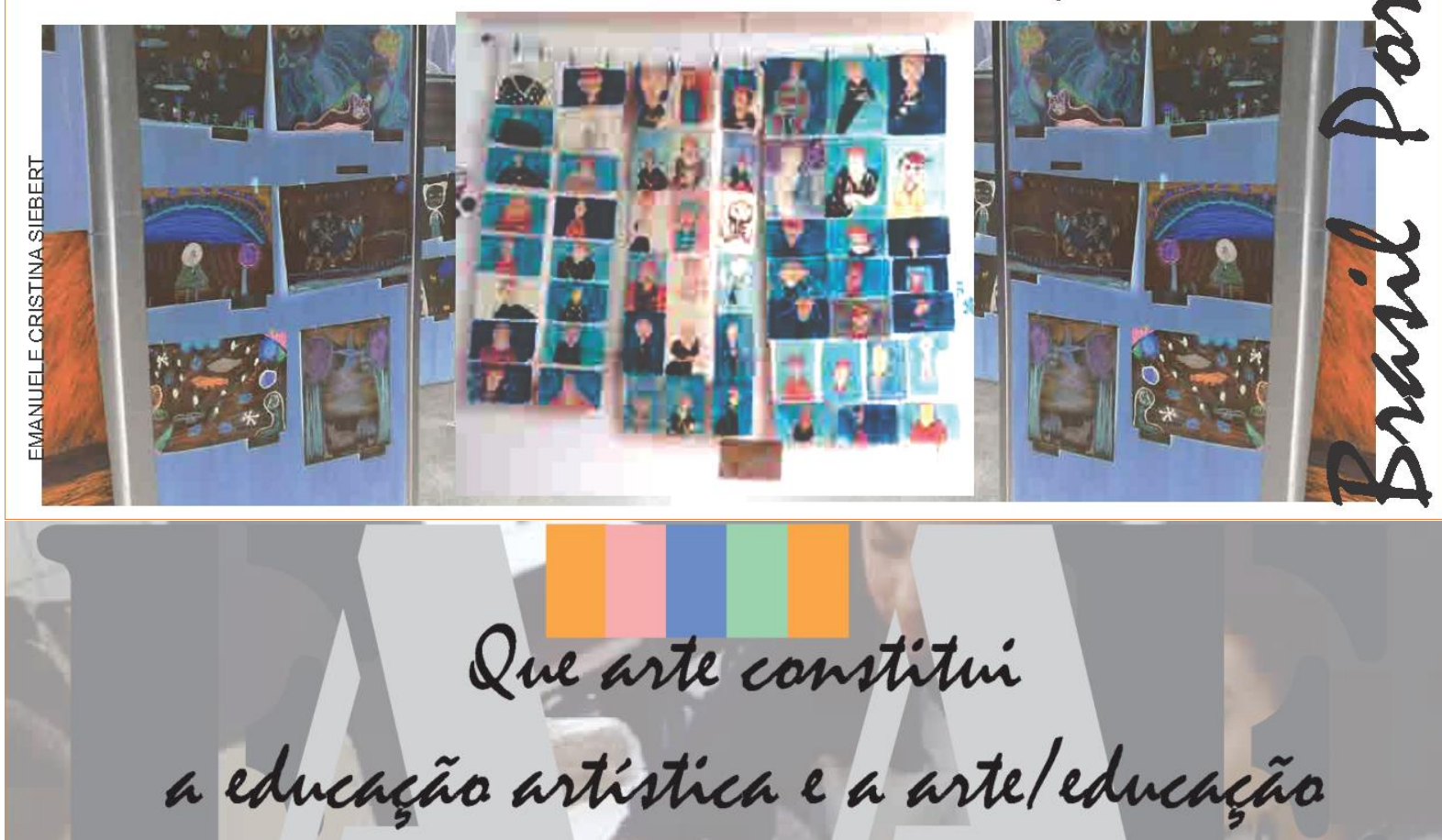
apresentadas no VII Congressa Matéria-Prima? 1 a arte que constitui um universo inserido no universo da cultura; a arte que é interdisciplinar, interagindo com a cultura popular e o multiculturalismo, além de envolver a tradição e a contemporaneidade; a arte constituída por um processo de criação estendido em um ato criador que abrange o indivíduo/coletivo e a fruição/mediação; a arte constituída por uma linguagem que se faz na história e que necessita da atualidade do corpo e do pensamento, envolvendo o gesto na multiplicação dos instrumentos e dos espaços;

a arte que é a linguagem da criação e da exposição, sendo imediata e mediada simultaneamente, através de uma imagem que também é texto.

BARRETO, Umbelina Maria Duarte. Portugal, Educação Artística, Arte/Educação, Brasil.

597

Revista GEARTE, Porto Alegre, v. 5, n. 3, p. 591-599, set./dez. 2018.

Disponível em: http://seer.ufrgs.br/gearte 
Transformar, criar, desafiar: este é o tema do VII Congresso Matéria-Prima, realizado em Lisboa, Portugal, em 2018. As apresentações do congresso possibilitaram a presente reflexão realizada no formato de Ensaio Visual.

Inicia-se com uma pergunta, que funciona como uma chave de abertura. $O$ ensaio perpassa pelo questionamento do discurso educativo e pelo levantamento de epistemologias da arte, que envolvem a educação artística e a arte/educação que se fizeram presentes nas apresentações do congresso.

Toda a exposição desse ensaio foi mediada por uma seleção que atendeu a alguns objetivos traçados em que se buscou uma relação Brasil/Portugal. Enfatiza-se a Arte/educação e a Educação artística, como nomenclaturas utilizadas em um e em outro país, relacionando as semelhanças e as diferenças encontradas nas práticas de ensino de arte, como uma das possibilidades da reflexão realizada.

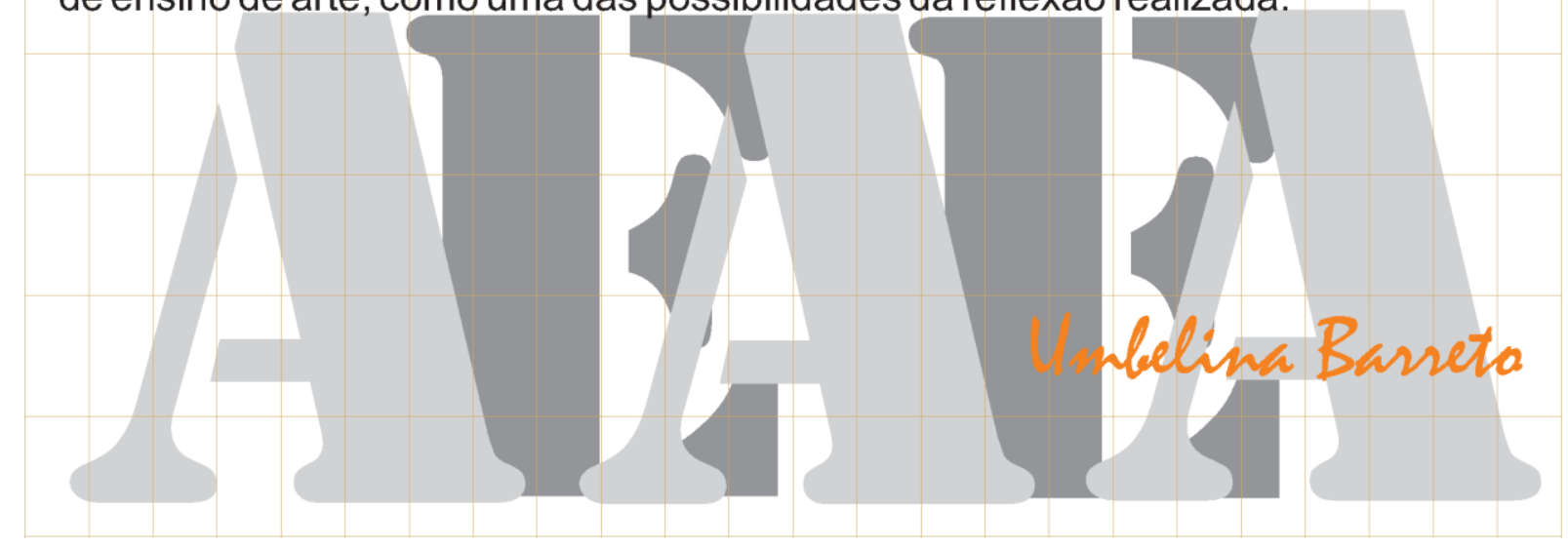

\section{Referências}

GUIMARÃES, Alexandre H. Monteiro; FRADE, Isabela Nascimento. Espaço Crítico: Discursividades sobre a (In)visibilidade Indigena na Escola. In: Atas do VII Congresso Matéria-Prima. Universidade de Lisboa, Lisboa, 2018. p.56-73.

HOFSTAETTER, Andrea.Por materiais didáticos propositivos e poéticos. In: Atas do VII Congresso Matéria-Prima.Universidade de Lisboa, Lisboa, 2018. p. 149-159.

PESSANHA, Ana Maria A.; SIMÕES, Anabela V. De Freitas. Exploração do Corpo em Movimento aplicando várias Formas e Técnicas de Expressão. In: Atas do VII Congresso Matéria-Prima. Universidade de Lisboa, Lisboa, 2018. p. 89-102.

PRATES, Ana Isabel De Sousa; LIMA, Inês Azinhais de. Desenvolver a expressividade e gesto na aula de Desenho-A. In: Atas do VII Congresso Matéria-Prima.Universidade de Lisboa, Lisboa, 2018. p. 83-88.

PRAZERES, Ana Cristina Rodrigues; MOREIRA, António Lopes. A participação em concursos e a colaboração com entidadeslocais como motivação para a aprendizagem. In: Atas do VII Congresso Matéria-Prima. Universidade de Lisboa, Lisboa, 2018. p.74-82.

QUEIROS, João Paulo (Org.). Atas do VII Congresso Matéria-Prima. Universidade de Lisboa, Lisboa, 2018. http://congressomateria.fba.ul.pt

SANCHES, Ana; ANDRADE, Bruno. lluminuras - llustração de Cantigas de amigo, amor e de escárnio e maldizer. In: Atas do VII Congresso Matéria-Prima.Universidade de Lisboa, Lisboa, 2018. p. 114-121.

SIEBERT, Emanuele Cristina. Exposições escolares em Portugal: A prática na contemporaneidade sob um olhar histórico. In: Atas do VII Congresso Matéria-Prima.Universidade de Lisboa, Lisboa, 2018. p. 264-274.

SILVA, Maria Cristina Da R. Fonseca Da; SHAH, Jaymini Pravinchandra. O ato criador como práxis arte/educativa na formação de professores de artes visuais. In: Atas do VII Congresso MatériaPrima.Universidade de Lisboa, Lisboa, 2018. p. 480-493. 


\section{Umbelina Maria Duarte Barreto}

Professora Aposentada do Instituto de Artes da Universidade do Rio Grande do Sul (UFRGS). Membro do Grupo de Pesquisa em Educação e Arte (GEARTE) -PPGEDU da Faculdade de Educação da UFRGS. Graduada em Artes Plásticas/ Habilitação Desenho e Pintura pela UFRGS. Mestre em Filosofia pela Pontifícia Universidade Católica do Rio Grande do Sul (PUCRS) e Doutora em Educação pela UFRGS. Possui experiência na área de Artes Visuais, com ênfase em Desenho e Pintura e tem realizado produção regular em poéticas visuais com exposições no Brasil e no Exterior. Na pesquisa tem atuado em ensino e pesquisa na linguagem do desenho e ensino e pesquisa em Semiótica Discursiva. Tem realizado pesquisas na área de Semiótica, Filosofia da Linguagem e Epistemologia da Arte.

Email: umbelina.barreto@ufrgs.br 